\title{
IL-36 cytokines in autoimmunity and inflammatory disease
}

\author{
Liping Ding ${ }^{1}$, Xiaohui Wang ${ }^{2}$, Xiaoping Hong ${ }^{1}$, Liwei Lu ${ }^{2}$ and Dongzhou Liu ${ }^{1}$ \\ ${ }^{1}$ Department of Rheumatology and Immunology, Shenzhen People's Hospital, The Second Clinical Medical College of Jinan \\ University, Shenzhen, China \\ ${ }^{2}$ Department of Pathology and Shenzhen Institute of Research and Innovation, The University of Hong Kong, Hong Kong, \\ China
}

Correspondence to: Dongzhou Liu, email: liu_dz2001@sina.com

Liwei Lu, email: liweilu@hku.hk

Keywords: interleukin-36; inflammatory disease; psoriasis; arthritis

Received: September 29, $2017 \quad$ Accepted: October 29, 2017

Published: December 01, 2017

Copyright: Ding et al. This is an open-access article distributed under the terms of the Creative Commons Attribution License 3.0 (CC BY 3.0), which permits unrestricted use, distribution, and reproduction in any medium, provided the original author and source are credited.

\section{ABSTRACT \\ The inteleukin-36 (IL-36) cytokines include IL-36a, IL-36 $\beta$, IL-36Y and IL- 36Ra, which belong to the IL-1 family and exert pro-inflammatory effects on various target cells such as keratinocytes, synoviocytes, dendritic cells and $\mathrm{T}$ cells. Emerging evidence has suggested a role of IL-36 in the pathogenesis of many inflammatory diseases. Here, we provide a brief review on the activation of IL-36 family cytokines and their involvement in autoimmunity and inflammatory diseases, which will provide further insights in understanding the functions of IL-36 family cytokines in the pathophysiology of autoimmunity and inflammatory diseases.}

\section{INTRODUCTION}

Interleukin (IL)-36, a novel member of IL-1 cytokine family, was initially identified by the DNA database screens searching for homologs to IL-1 in 1999. Upon the elucidation of its biological function, each of these IL-1 family members has been assigned an individual interleukin designation [1]. IL-36 cytokines consist of four members, with IL-36 $\alpha$, IL-36 3 , and IL-36 $\gamma$ acting as IL-36 receptor agonists, while IL-36 receptor antagonist (Ra) is a cytokine that inhibits the activation of IL-36 receptor (IL-36R) signaling. IL-36 cytokines bind to the IL-36R and use the IL-1 receptor accessory protein (IL$1 \mathrm{RAcP})$ as a co-receptor. Functionally, IL-36 cytokines exert pro-inflammatory effects, with certain differential functions depending on the type and site of inflammation. Since their abundant expression in keratinocytes (KCs) of skin and correlation with Th1 and Th17 cytokines in human psoriatic skin lesions, IL-36 cytokines have been best characterized in models of psoriasis [2]. Over the past years, the pathological effects of IL-36 family cytokines have been extended to a variety of inflammatory diseases, including psoriatic arthritis (PsA), systemic lupus erythematosus (SLE), inflammatory bowel disease (IBD), ulcerative colitis and Crohn's disease [1-6]. Furthermore, IL-36 cytokines also respond to various inflammatory signals induced by microbial infections, suggesting a role of these cytokines in anti-microbial inflammation [7]. In this review, we aim to discuss recent research on the role and mechanisms of IL-36 in regulating the immunity and inflammatory disease, which may provide the rationale for the development of IL-36-targeted therapies for treating psoriasis and other inflammatory diseases.

\section{IL-36 processing and secretion}

The IL-36 cytokines are expressed in a variety of cell types, with abundant expression in $\mathrm{KCs}$, bronchial epithelium, neuron cells, glial cells, dendritic cells (DCs) and macrophages, suggesting an important role of IL-36 cytokines in the homoeostasis and inflammation of the related tissues [2-4]. The activities of the N-terminal domain truncated IL-36 $\alpha$, IL-36 $\beta$ and IL-36 $\gamma$ increased by more than 1000-fold in comparison to their non-mutant forms [8]. The protein structure surrounding the truncation sites resembles proteases site other than caspase- 1 cleaving site. Recently, Cathepsin S was demonstrated as the major IL-36y-activating protease expressed by barrier tissues [9]. Several studies have reported that epidermal growth factor activates the predominant production of IL-36 $\alpha$ and IL-36 $\beta$ in the skin, indicating the contribution of IL-36 cytokines in the skin homeostasis [10]. Stimulations with ligands for TLR2 and TLR4 such as LPS from Escherichia Coli and Porphyromonas gingivalis induce significant production of IL-36 $\gamma$, TNF $\alpha$, IL-6 and IL-32 in a human monocytic cell line (THP-1), and revealing an involvement 
of IL-36 in regulating innate immunity [11]. In various models of asthma, IL-36 cytokines are produced by lung epithelial cells in response to various inflammatory stimuli [12-13]. Moreover, peripheral blood lymphocytes are able to express IL-36 $\gamma$ upon stimulation of $\alpha$-particles whereas $\mathrm{T}$ lymphocytes have been reported to express the IL-36 agonists under specific conditions [14]. Notably, IL$36 \alpha$ is upregulated in synovium-infiltrated plasma cells of PsA and rheumatoid arthritis (RA) patients, linking plasma cells to inflammatory cytokine production [15]. In cultured human $\mathrm{KCs}$, IL-36 cytokines can also induce the expression of themselves in an autocrine loop similar to IL-1, underscoring its potent proinflammatory property [16]. Together, these findings indicate that IL-36 cytokines are secreted in a stimulus-dependent manner comparable to the induction of other IL-1 cytokines. However, the regulatory mechanisms underlying the production of IL36 cytokines under different conditions still remain to be elucidated.

\section{IL-36 receptor and signaling pathway}

IL-1F5, IL-1F6, IL-1F8, and IL-1F9, which are

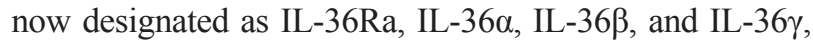
respectively. These four novel members, collectively called IL-36 cytokines, are part of the IL-1 family [17]. The encoding genes of these cytokines are located on the human chromosome 2q13 within $360 \mathrm{~kb}$ region [13-14]. All these cytokines bind to IL-1 receptor (IL-1R)-related protein2.

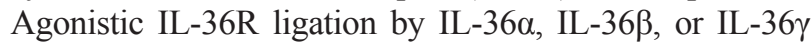
leads to the recruitment of IL-1RAcP, the common accessory protein of IL-1, resulting in the activation of signaling pathway similar to those induced by IL-1 $\alpha$ and IL-1 $\beta$ [16]. IL-36 $\gamma$ is reported to activate NF- $\kappa$ B in Jurkat cells in an IL-36R-dependent manner [18]. Subsequent studies have shown that IL-36 $\alpha$, IL-36 $\beta$ and IL-36 $\gamma$, bind to IL-1Rrp2 and employ IL-1RAcP as a co-receptor in Jurkat cells as well as in several other human and mouse cell lines [19].

IL-36Ra, sharing more than 50\% homology with IL-1 receptor antagonist (IL-1Ra), has been reported to elicit its antagonist activity through binding to the IL36R and preventing the recruitment of IL-1RAcP [17]. Animal studies using gene deficient mice show that the anti-inflammatory effect of IL-36Ra on LPS-induced IL$1 \beta$ is dependent on the IL-4 induction and recruitment of the anti-inflammatory SIGIRR/TIR8 [20]. These findings suggest that IL-36Ra plays anti-inflammatory role via its specific signaling pathway. Since IL-1Ra has not been found to induce cytokine production, IL-36Ra acts differently from the classical antagonist IL-1Ra.

The IL-36R is expressed by various cell types, including $\mathrm{KCs}$, monocytes, $\mathrm{DCs}$, and $\mathrm{CD}^{+} \mathrm{T}$ lymphocytes [13]. Published studies identifying the corresponding receptor and expression cells of the IL-36 cytokines are summarized in Table 1. Recent studies have revealed that human KCs contain IL-1RAcP. Notably, significant positive correlations have been observed among the protein expression of IL-36 cytokines with phosphorylated p38 MAPK and NF- $\mathrm{B}$ p65 in psoriatic skin lesions. Moreover, the increased expression of IL-36 cytokines in psoriatic skin lesions may further amplify the activation of MAPK and NF- $\mathrm{B}$ pathways [17, 21], indicating that IL-36 cytokines, similar to other IL-1 family members, can activate the MAPK and NF- $\kappa \mathrm{B}$ pathways by binding to the corresponding receptor, IL-1RAcP.

\section{The biological functions of IL-36 family cytokines}

The IL-36 agonists, IL-36 $\alpha$, IL-36 $\beta$ and IL-36 $\gamma$, bind to the same receptor complex (IL-1Rrp2 and IL-1RAcP) to initiate proinflammatory signal transduction through the IL-36R. However, the biological functions of the IL-36 agonists are negatively regulated by IL-36Ra [29, 32]. IL36 cytokines are found in $\mathrm{KCs}$, bronchial epithelium, brain tissue, monocytes and macrophages [4]. Additionally, IL-36R responds to IL-36 agonists and is constitutively expressed by both bone marrow-derived dendritic cells (BMDCs) and $\mathrm{CD}^{+} \mathrm{T}$ lymphocytes, which have been shown as the major cell targets of IL-36 [10]. Emerging evidence indicates that IL-36 signaling is involved in the activation of innate and adaptive immune responses. DCs play a critical role in modulating the balance between immune tolerance and autoimmune inflammation, bridging the innate and adaptive arms of the immune system. Importantly, DCs possess the potent capacity in priming helper T (Th) cell differentiation. In murine DCs, IL-36 agonists upregulate maturation-associated CD80, CD86 and MHCII and induce the production of IL-12, IL-1 $\beta$, IL6 , TNF- $\alpha$ and IL-23 in an IL-36R-dependent fashion. IL36 agonists also enhance IL-36R-expressing $\mathrm{CD}^{+} \mathrm{T}$ cells to produce IFN- $\gamma$, IL-4, and IL-17A in a dose dependent manner [22]. The interaction between Th1 cytokines and IL-36 has also been well demonstrated in murine $\mathrm{CD}^{+}$ T cells. IL-36 not only induces the production of IFN- $\gamma$ in cultured splenocytes and activated $\mathrm{CD}^{+} \mathrm{T}$ cells, but also acts as an adjuvant to stimulate type $1 \mathrm{~T}$ helper (Th1) response in mice intradermally immunized using BSA [22]. Moreover, IL-36 agonists can directly polarize the differentiation of IFN- $\gamma$-producing Th1 cells [33]. The direct induction of IL-17A by IL-36 agonists is observed in cultured murine $\mathrm{CD}^{+} \mathrm{T}$ cells [22]. It has been shown that TNF- $\alpha$ and Th17 cytokines such as IL-17A and IL-22 directly induce IL-36 cytokines and, in turn, enhance their own expression and the production of proinflammatory cytokines such as TNF- $\alpha$, IL- 6 and IL- 8 in cultured human $\mathrm{KCs}$, forming a positive feedback loop between IL-36 and Th17 cytokines [16]. The increased gene expression of IL36 is also found to be correlated with Th17 cytokines in the skin lesions of psoriatic patients. [16]. These studies have indicated a pathogenic role of IL-36 cytokines in psoriasis by driving Th1 and Th17 responses. 
Table 1: An overview of the IL-36 cytokines

\begin{tabular}{|c|c|c|c|c|}
\hline $\begin{array}{l}\text { IL-36 } \\
\text { cytokines }\end{array}$ & $\begin{array}{l}\text { Alternative } \\
\text { names }\end{array}$ & Corresponding receptor & Expression cells & References \\
\hline IL-36 $\alpha$ & IL-IF6 & IL-1Rrp2 and IL-1RAcP & Monocytes, T/B-lymphocytes, & [22-24] \\
\hline 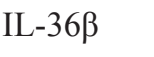 & IL-IF8 & IL-1Rrp2 and IL-1RAcP & Monocytes, T/B-lymphocytes & {$[25-27]$} \\
\hline 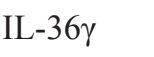 & IL-IF9 & IL-1Rrp2and IL-1RAcP & keratinocytes, epithelial cells & [28-30] \\
\hline IL-36Ra & IL-IF5 & Binds IL-1Rrp2 to SIGIRR & keratinocytes, Monocytes, DCs & {$[16,22,31]$} \\
\hline
\end{tabular}

\section{Roles of IL-36 cytokines in inflammatory diseases}

Over the past two decades, IL-36 cytokines have been implicated in the development of various human diseases. With a recognized central role in regulating inflammation, IL-36 cytokines mediate many inflammatory diseases, including skin diseases, inflammatory arthritis and pulmonary disorders. Available evidence suggests that IL-36 cytokines contribute to the pathogenesis of human diseases owing to their unique functions exerted between the agonists and antagonists.

\section{IL-36 in psoriasis}

Psoriasis, as a chronic inflammatory skin disorder affecting approximately $2 \%$ of the world's population, is considered as a T-cell driven disease. Both Th 1, Th17 cells and $\gamma \delta \mathrm{T}$ cells have been demonstrated to participate in psoriasis pathogenesis. Dermal $\gamma \delta \mathrm{T}$ cells, as one of the major drivers of psoriasis pathology, are the major source of IL-17A in the skin upon IL-23 stimulation [34-35]. It has been shown that the psoriatic skin lesions highly express IL-36 cytokines whereas IL-36 agonists activate DCs and play a role in polarizing T-helper responses [24]. IL-36 $\alpha$, IL-36 $\beta$ and IL-36 $\gamma$ are highly expressed in skin and are involved in the pathogenesis of inflammatory skin disease psoriasis, whereby IL-36 $\gamma$ could be activated by cathepsin $\mathrm{S}$ expressed in epithelial cells, while the antagonists IL-36Ra or IL-38, another potential IL-36 inhibitor, limit uncontrolled inflammation [25-26]. Animal studies using IL-36R-deficient $\left(I l 36 r^{-/}\right)$mice showed that deficiency of IL-36Rresulted in reduced dermal IL$17 \mathrm{~A}$-producing $\gamma \delta \mathrm{T}$ cells and ameliorated psoriasiform dermatitis in imiquimod-induced mice [35]. The critical role of IL-36 cytokines in regulating skin inflammation is also underscored by the striking evidence that transgenic mice overexpressing IL-36 $\alpha$ in basal KCs spontaneously exhibit skin lesions similar to psoriasis [3]. Moreover, IL-36Ra deficiency in IL-36 $\alpha$ transgenic mice results in exacerbation of the skin manifestation, further validating the antagonistic effect of IL-36Ra on skin inflammation induced by IL-36 agonists [3]. In human psoriasis skin lesions, IL-36 gene expression is positively correlated with Th17 cytokines. The IL-36 agonists can promote the production of pro-inflammatory mediators IL-17A, IL-22, IFN- $\gamma$, TNF- $\alpha$, IL-6, IL-8 and also themselves in
KCs [16]. Furthermore, IL-36 agonists potently promote human KCs to express various chemokines such as CCL15, CCL17, CCL20, CCL22, and CXCL8 in vitro [36]. Intradermal injections of IL-36 $\alpha$ lead to substantial local inflammation characterized by chemokine expression, leukocyte infiltration and acanthosis of mouse skin, further supporting a role of IL-36 in facilitating immune cell recruitment to inflamed skin [36]. In line with this evidence, patients with mutations in the IL-36RN gene encoding a nonfunctional IL-36Ra protein suffer from severe generalized pustular psoriasis [37], whereas anti-TNF- $\alpha$ therapy in patients with psoriasis shows significantly improved outcomes, which is associated with decreased levels of IL-36 cytokines in the skin lesions [25]. Thus, available results suggest that IL-36 cytokines actively regulate skin inflammation via activating $\mathrm{KCs}$ and mediating DC-T cell interaction, which result in tissue infiltration, cell activation and abnormal proliferation, contributing to major characteristic hallmarks of human psoriasis.

\section{IL-36 in arthritis}

PsA is the major comorbidity of psoriasis. Approximately $20-30 \%$ of psoriasis patients develop PsA, in which skin lesions classically precede joint symptoms [38]. The genomic profiling of IL-17A, IFN- $\gamma$ and TNF- $\alpha$ in PsA synovium shows much stronger correlation with IL-36 gene expression in PsA skin than other forms of arthritis [39]. In addition, the expression of IL-17 receptor (IL-17R) in the synoviocytes of PsA patients is significantly increased compared to that in synoviocytes of osteoarthritis patients, with concomitant augment in the number of Th17 cells in the synovial fluid, peripheral blood and skin tissue of PsA patients [39]. In the synovial tissue, IL-36 $\alpha$, mainly detected in CD138-positive plasma cells, was expressed at significantly higher levels in synovium of PsA and RA than that in OA. No differences were observed for the expression levels of IL-36R and IL36Ra between PsA, RA and OA [5]. IL-36 $\alpha$ links plasma cells to inflammatory cytokine production such as IL-6 and IL- 8 by synovial fibroblasts, which may represent a key link between IL-36 and the induction of synovitis.

Currently, the role of IL-36 cytokines in RA is still controversial. In the synovium of CIA mice and RA

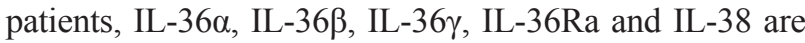
all upregulated and correlated with the expression of IL- 
Table 2: IL-36 cytokine expression in inflammatory diseases

\begin{tabular}{|c|c|c|c|}
\hline Diseases categories & IL-36 isoforms & Expression tissues & references \\
\hline Psoriasis & IL-36 $\alpha, \beta$ and $\gamma$ & skin & {$[14,42]$} \\
\hline PsA & IL-36a, IL-36Ra & synovium & [13] \\
\hline RA & IL-36 $\alpha, \beta$ and $\gamma$ & synovium & [43] \\
\hline SLE & 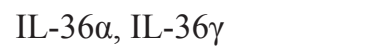 & blood & [44] \\
\hline pSS & IL-36 $\alpha$,IL-36Ra, IL-36RA & labial salivary glands & [45] \\
\hline IBD & 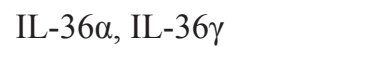 & colonic mucosa & {$[1,46]$} \\
\hline ILD & 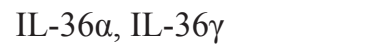 & lung & {$[47,48]$} \\
\hline Obesity & IL-36 $\alpha$ & adipose tissue & [49] \\
\hline
\end{tabular}

1ß, CCL3, CCL4 and M-CSF, but not with Th17 cytokines [30]. In addition, IL-36R blocking antibody treatment does not modify clinical onset and pattern of disease in arthritic mice. Moreover, the histological features of TNFinduced arthritis have not been changed by blocking IL-36 signaling pathways [40]. Furthermore, the disease severity in collagen-induced arthritis (CIA) mice is not attenuated by neutralizing anti-IL-36R antibody [41]. Thus, these findings suggest that IL-36 signaling is not essentially involved in the development of experimental autoimmune arthritis.

\section{IL-36 in other inflammatory diseases}

IL-36 family cytokines have emerged as important pro-inflammatory mediators in many inflammatory diseases.
As summarized in Table 2, Recent studies show that IL-36 cytokines are produced by various cell types such as KCs, CD68 ${ }^{+}$macrophages, DCs and CD79 $\alpha^{+}$plasma cells in skin, synovium, joints and colonic mucosa tissues [30]. Plasma concentrations of IL-36 $\alpha$ and IL-36 $\gamma$ are significantly increased in active SLE patients compared with healthy subjects, which are positively correlated with SLE disease activity and elevated plasma IL-10 concentration [31]. In patients with primary Sjögren's Syndrome, IL-36 $\alpha$ levels are significantly increased in the blood and salivary glands, which are correlated with the serum levels of IL-17A and IL-22 [32]. In addition, recent studies have found that IL-36 $\alpha$ and IL-36 $\beta$ induce neutrophil influx in mouse lungs and act as pro-inflammatory cytokines in the lung in vivo [47-48]. Levels of IL-36 $\alpha$ and IL-36y are significantly elevated in the colonic mucosa of patients

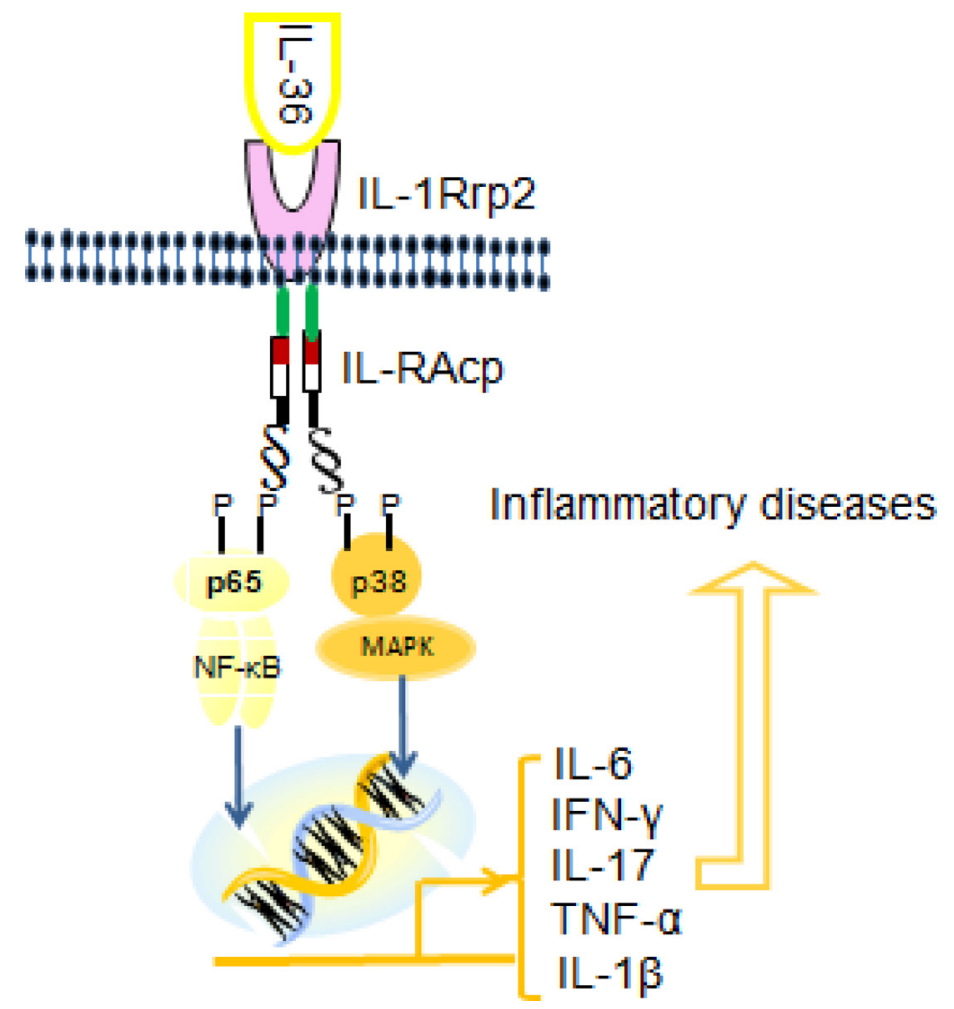

Figure 1: The signaling pathway of IL-36 cytokines. 
with inflammatory bowel disease (IBD) and particularly, in ulcerative colitis [3]. Moreover, the elevated IL-36 expression is mirrored in the inflamed colonic mucosa of mice, whereas IL-36R deficiency results in reduced disease severity and decreased infiltration of innate inflammatory cell to the colon lamina propria in an acute dextran sulfate sodium (DSS)induced model of colitis [6]. In patients with Crohn's disease, IL-36 $\gamma$ induces TNF- $\alpha$ expression in KCs and sustains a selfamplifying pro-inflammatory loop with IL-17C by inducing its own expression and IL-17C [5]. In CIA mice and RA patients, levels of IL-36 $\alpha$, IL-36 $\beta$ and IL-36 $\gamma$ expression are enhanced in inflamed joints [30]. These findings suggest that IL-36 cytokines play important roles in inflammatory diseases.

\section{CONCLUSIONS}

Both IL-36 cytokines and IL-36R signaling pathway share key features of the IL-1 and IL-1R pathway. However, the disease manifestations caused by mutations of ILIRa and IL36Ra genes in humans suggest that the functions of these two genes have non-redundant properties. Furthermore, IL-36R is expressed in a morerestricted way than IL-1R and shows a tendency to regulate tissue-specific inflammatory responses. Therefore, IL-36 cytokines are not simple surrogates of IL-1. Instead, they are evolved to regulate tissue specific immune responses. During recent years, much has been learned about IL-36 cytokines and their role in inflammation As showed in Figure 1. Although Th17 cytokines (IL-17A and IL-22) and Th1 cytokines (IFN- $\gamma$ and TNF- $\alpha$ ) are known to play a key role in the pathogenesis of inflammatory diseases. IL-36 potently induces the production of TH1 and Th17 cytokines, which in turn enhances the function of IL-36 cytokines in an autocrine manner to form an amplification loop. Apart from their crucial role in regulating skin inflammation, IL-36 cytokines also show the important functions in inflammatory conditions of lung tissue, joint synovium and colonic mucosa tissues to promote inflammation in the skin lesion, arthritis and bowel diseases. However, further investigations are needed to elucidate the molecular mechanisms underlying their biological functions. In terms of clinical implications, future elucidation of the functions of IL-36 family cytokines in disease pathogenesis may facilitate the development of therapeutic targeting of these cytokines for the treatment of inflammatory disorders.

\section{CONFLICTS OF INTEREST}

The authors declare no conflicts of interest.

\section{FUNDING}

This work was supported by grants from Shenzhen Science and Technology Research Foundation (JCYJ20160422154407256), Shenzhen Health Plan
Committee Research Foundation (201601014), Sanming project of medicine in Shenzhen, the group of Rheumatology and Immunology leaded by Xiaofeng Zeng of Peking Union medical college Hospital and Dongzhou Liu in Shenzhen People's Hospital (SYJY201704 and SYJY201705) National Basic Research Program of China (973 program, No. 2014CB541904) and National Natural Science Foundation of China (No. 81373195, 81771761 and 91442116).

\section{REFERENCES}

1. Nishida A, Hidaka K, Kanda T, Imaeda H, Shioya M, Inatomi O, Bamba S, Kitoh K, Sugimoto M, Andoh A. Increased expression of interleukin-36, a member of the interleukin-1 cytokine family, in inflammatory bowel disease. Inflammatory bowel diseases. 2016; 22:303-314.

2. Towne JE, Sims JE. Il-36 in psoriasis. Current opinion in pharmacology. 2012; 12:486-490.

3. Blumberg H, Dinh H, Trueblood ES, Pretorius J, Kugler D, Weng N, Kanaly ST, Towne JE, Willis CR, Kuechle MK, Sims JE, Peschon JJ. Opposing activities of two novel members of the IL-1 ligand family regulate skin inflammation. The Journal of experimental medicine. 2007; 204:2603-2614.

4. van de Veerdonk FL, Netea MG. New insights in the immunobiology of IL-1 family members. Frontiers in immunology. 2013; 4:167.

5. Frey S, Derer A, Messbacher ME, Baeten DL, Bugatti S, Montecucco C, Schett G, Hueber AJ. The novel cytokine interleukin-36 $\alpha$ is expressed in psoriatic and rheumatoid arthritis synoviumpsoriatic arthritis. Ann Rheum Dis. 2013; 72:1569-1574.

6. Friedrich M, Tillack C, Wollenberg A, Schauber J, Brand S. IL-36gamma sustains a proinflammatory self-amplifying loop with IL-17c in anti-TNF-induced psoriasiform skin lesions of patients with crohn's disease. Inflammatory bowel diseases. 2014; 20:1891-1901.

7. Segueni N, Vigne S, Palmer G, Bourigault ML, Olleros ML, Vesin D, Garcia I, Ryffel B, Quesniaux VF, Gabay C. Limited contribution of IL-36 versus IL-1 and TNF pathways in host response to mycobacterial infection. PloS one. 2015; 10: e0126058.

8. Towne JE, Renshaw BR, Douangpanya J, Lipsky BP, Shen M, Gabel CA, Sims JE. Interleukin-36 (IL-36) ligands require processing for full agonist (IL-36alpha, IL-36beta, and IL-36gamma) or antagonist (IL-36Ra) activity. Journal of Biological Chemistry. 2011; 286:42594-42602

9. Ainscough JS, Macleod T, McGonagle D, Brakefield R, Baron JM, Alase A, Wittmann M, Stacey M. Cathepsin S is the major activator of the psoriasis-associated proinflammatory cytokine IL-36y. Proc Natl Acad Sci USA. 2017;114:E2748-E2757.

10. Franzke CW, Cobzaru C, Triantafyllopoulou A, Loffek S, Horiuchi K, Threadgill DW, Kurz T, van Rooijen N, 
Bruckner-Tuderman L, Blobel CP. Epidermal ADAM17 maintains the skin barrier by regulating egfr liganddependent terminal keratinocyte differentiation. The Journal of experimental medicine. 2012; 209:1105-1119.

11. Barksby HE, Nile CJ, Jaedicke KM, Taylor JJ, Preshaw PM. Differential expression of immunoregulatory genes in monocytes in response to porphyromonas gingivalis and escherichia coli lipopolysaccharide. Clinical and experimental immunology. 2009; 156:479-487.

12. Bochkov YA, Hanson KM, Keles S, Brockman-Schneider RA, Jarjour NN, Gern JE. Rhinovirus-induced modulation of gene expression in bronchial epithelial cells from subjects with asthma. Mucosal immunology. 2010; 3:69-80.

13. Gabay C, Towne JE. Regulation and function of interleukin-36 cytokines in homeostasis and pathological conditions. Journal of leukocyte biology. 2015; 97:645-652.

14. Yang J, Meyer M, Muller AK, Bohm F, Grose R, Dauwalder T, Verrey F, Kopf M, Partanen J, Bloch W, Ornitz DM, Werner S. Fibroblast growth factor receptors 1 and 2 in keratinocytes control the epidermal barrier and cutaneous homeostasis. The Journal of cell biology. 2010; 188:935952.

15. Frey S, Derer A, Messbacher ME, Baeten DL, Bugatti S, Montecucco C, Schett G, Hueber AJ. The novel cytokine interleukin-36alpha is expressed in psoriatic and rheumatoid arthritis synovium. Annals of the rheumatic diseases. 2013; 72:1569-1574.

16. Carrier Y, Ma HL, Ramon HE, Napierata L, Small C, O'Toole M, Young DA, Fouser LA, Nickerson-Nutter C, Collins M, Dunussi-Joannopoulos K, Medley QG. Interregulation of th17 cytokines and the il-36 cytokines in vitro and in vivo: Implications in psoriasis pathogenesis. The Journal of investigative dermatology. 2011; 131:2428-2437.

17. Gresnigt MS, van de Veerdonk FL. Biology of il36 cytokines and their role in disease. Seminars in Immunology. 2013; 25:458-465.

18. Debets R, Timans JC, Homey B, Zurawski S, Sana TR, Lo S, Wagner J, Edwards G, Clifford T, Menon S, Bazan JF, Kastelein RA. Two novel IL-1 family members, IL-1 delta and IL-1 epsilon, function as an antagonist and agonist of nf-kappa B activation through the orphan IL-1 receptorrelated protein 2. J Immunol. 2001; 167:1440-1446.

19. Towne JE, Garka K, Renshaw BR, Virca GD, Sims JE. Interleukin (IL)-1F6, IL-1F8, and IL-1F9 signal through IL1Rrp2 and IL-1RAcp to activate the pathway leading to NFkappa B and MAPKs. J Biol Chem. 2004; 279:13677-13688.

20. Riva F, Bonavita E, Barbati E, Muzio M, Mantovani A, Garlanda C. TIR8/SIGIRR is an Interleukin-1 Receptor/ Toll like receptor family member with regulatory functions in inflammation and immunity. Frontiers in immunology. 2012; 3:322.

21. Costelloe C, Watson M, Murphy A, McQuillan K, Loscher C, Armstrong ME, Garlanda C, Mantovani A, O'Neill LA, Mills KH, Lynch MA. IL-1F5 mediates anti-inflammatory activity in the brain through induction of IL-4 following interaction with SIGIRR/TIR8. Journal of neurochemistry. 2008; 105:1960-1969.

22. Vigne S, Palmer G, Lamacchia C, Martin P, Talabot-Ayer D, Rodriguez E, Ronchi F, Sallusto F, Dinh H, Sims JE, Gabay C. IL-36R ligands are potent regulators of dendritic and T cells. Blood. 2011; 118:5813-5823.

23. Nicklin MJ, Barton JL, Nguyen M, FitzGerald MG, Duff GW, Kornman K. A sequence-based map of the nine genes of the human interleukin-1 cluster. Genomics. 2002; 79:718-725.

24. Martin U, Scholler J, Gurgel J, Renshaw B, Sims JE, Gabel CA. Externalization of the leaderless cytokine il-1f6 occurs in response to lipopolysaccharide/atp activation of transduced bone marrow macrophages. J Immunol. 2009; 183:4021-4030.

25. Johnston A, Xing X, Guzman AM, Riblett M, Loyd CM, Ward NL, Wohn C, Prens EP, Wang F, Maier LE, Kang S, Voorhees JJ, Elder JT, et al. IL-1F5, -F6, -F8, and -F9: A novel IL-1 family signaling system that is active in psoriasis and promotes keratinocyte antimicrobial peptide expression. J Immunol. 2011; 186:2613-2622.

26. Magne D, Palmer G, Barton JL, Mézin F, Talabot-Ayer D, Bas S, Duffy T, Noger M, Guerne PA, Nicklin MJ, Gabay C. The new IL-1 family member IL-1F8 stimulates production of inflammatory mediators by synovial fibroblasts and articular chondrocytes. Arthritis research \& therapy. 2006; 8:R80.

27. Turtoi A, Brown I, Schlager M, Schneeweiss FH. Gene expression profile of human lymphocytes exposed to (211) at alpha particles. Radiat Res. 2010; 174:125-136.

28. Ritchlin C, Haas-Smith SA, Hicks D, Cappuccio J, Osterland CK, Looney RJ. Patterns of cytokine production in psoriatic synovium. J Rheumatol. 1998; 25:1544-1552.

29. Chustz RT, Nagarkar DR, Poposki JA, Favoreto S Jr, Avila PC, Schleimer RP, Kato A. Regulation and function of the IL-1 family cytokine IL-1F9 in human bronchial epithelial cells. American journal of respiratory cell and molecular biology 2011; 45:145-153.

30. Berglöf E, Andre R, Renshaw BR, Allan SM, Lawrence CB, Rothwell NJ, Pinteaux E. IL-1Rrp2 expression and IL-1F9 (IL-1H1) actions in brain cells. Journal of neuroimmunology. 2003; 139:36-43.

31. Gresnigt MS, van de Veerdonk FL. Biology of IL36 cytokines and their role in disease. Seminars in immunology. 2013; 25:458-465.

32. Dinarello C, Arend W, Sims J, Smith D, Blumberg H, O'Neill L, Goldbach-Mansky R, Pizarro T, Hoffman H, Bufler P, Nold M, Ghezzi P, Mantovani A, et al. IL-1 family nomenclature. Nature immunology. 2010; 11:973.

33. Vigne S, Palmer G, Martin P, Lamacchia C, Strebel D, Rodriguez E, Olleros ML, Vesin D, Garcia I, Ronchi F, Sallusto F, Sims JE, Gabay C. IL-36 signaling amplifies Th1 responses by enhancing proliferation and Th1 polarization of naive CD4+ T cells. Blood. 2012; 120:3478-3487. 
34. Cai Y, Fleming C, Yan J. Dermal $\gamma \delta$ T cells--a new player in the pathogenesis of psoriasis. Int Immunopharmacol. 2013; 16:388-391.

35. Tortola L, Rosenwald E, Abel B, Blumberg H, Schäfer M, Coyle AJ, Renauld JC, Werner S, Kisielow J, Kopf M. Psoriasiform dermatitis is driven by IL-36 mediated DCkeratinocyte crosstalk. J Clin Invest. 2012; 122:3965-3976.

36. Foster AM, Baliwag J, Chen CS, Guzman AM, Stoll SW, Gudjonsson JE, Ward NL, Johnston A. IL-36 promotes myeloid cell infiltration, activation, and inflammatory activity in skin. J Immunol. 2014; 192:6053-6061.

37. Marrakchi S, Guigue P, Renshaw BR, Puel A, Pei XY, Fraitag S, Zribi J, Bal E, Cluzeau C, Chrabieh M, Towne JE, Douangpanya J, Pons C, et al. Interleukin-36-receptor antagonist deficiency and generalized pustular psoriasis. The New England journal of medicine. 2011; 365:620-628.

38. Busse K, Liao W. Which psoriasis patients develop psoriatic arthritis? Psoriasis Forum. 2010; 16:17-25.

39. Belasco J, Louie JS, Gulati N, Wei N, Nograles K, FuentesDuculan J, Mitsui H, Suárez-Fariñas M, Krueger JG. Comparative genomic profiling of synovium versus skin lesions in psoriatic arthritis. Arthritis Rheumatol. 2015;67: 934-944.

40. Derer A, Groetsch B, Harre U, Bohm C, Towne J, Schett G, Frey S, Hueber AJ. Blockade of IL-36 receptor signaling does not prevent from TNF-induced arthritis. PloS one. 2014; 9:e101954.

41. Lamacchia C, Palmer G, Rodriguez E, Martin P, Vigne S, Seemayer CA, Talabot-Ayer D, Towne JE, Gabay C. The severity of experimental arthritis is independent of IL-36 receptor signaling. Arthritis Res Ther. 2013; 15:R38

42. Ainscough JS, Macleod T, McGonagle D, Brakefield R, Baron JM, Alase A, Wittmann M, Stacey M. Cathepsin $\mathrm{S}$ is the major activator of the psoriasis-associated proinflammatory cytokine IL-36 $\gamma$. Proc Natl Acad Sci U S A. 2017; 114:E2748-E2757.
43. Boutet MA, Bart G, Penhoat M, Amiaud J, Brulin B, Charrier C, Morel F, Lecron JC, Rolli-Derkinderen M, Bourreille A, Viqne S, Gabay C, Palmer G, et al. Distinct expression of interleukin (IL)-36alpha, beta and gamma, their antagonist IL-36Ra and IL-38 in psoriasis, rheumatoid arthritis and crohn's disease. Clinical and experimental immunology. 2016; 184:159-173.

44. Chu M, Wong CK, Cai Z, Dong J, Jiao D, Kam NW, Lam CW, Tam LS. Elevated expression and pro-inflammatory activity of IL-36 in patients with systemic lupus erythematosus. Molecules. 2015; 20:19588-19604.

45. Ciccia F, Accardo-Palumbo A, Alessandro R, Alessandri C, Priori R, Guggino G, Raimondo S, Carubbi F, Valesini G, Giacomelli R, Rizzo A, Triolo G. Interleukin-36alpha axis is modulated in patients with primary sjogren's syndrome. Clinical and experimental immunology. 2015; 181:230 238.

46. Russell SE, Horan RM, Stefanska AM, Carey A, Leon G, Aguilera M, Statovci D, Moran T, Fallon PG, Shanahan F, Brint EK, Melgar S, Hussey S, Walsh PT. IL-36alpha expression is elevated in ulcerative colitis and promotes colonic inflammation. Mucosal immunology. 2016; 9:11931204.

47. Ramadas RA, Ewart SL, Iwakura Y, Medoff BD, LeVine AM. IL-36 alpha exerts pro-inflammatory effects in the lungs of mice. PLoS One. 2012; 7: e45784.

48. Ramadas RA, Ewart SL, Medoff BD, LeVine AM. Interleukin-1 family member 9 stimulates chemokine production and neutrophil influx in mouse lungs. Am J Respir Cell Mol Biol. 2011; 44:134-145.

49. van Asseldonk EJ, Stienstra R, Koenen TB, van Tits LJ, Joosten LA, Tack CJ, Netea MG. The effect of the interleukin- 1 cytokine family members IL-1F6 and IL-1F8 on adipocyte differentiation. Obesity (Silver Spring). 2010; 18:2234-2236. 